\title{
Adsorption Isotherms and Kinetic Studies of Congo-Red Removal from Waste Water Using Activated Carbon Prepared from Jujube Seed
}

\author{
Idris Aminu*, Sani M. Gumel, Wasila A. Ahmad, Adamu A. Idris \\ Department of Pure and Industrial Chemistry, Faculty of Physical Sciences, College of Natural and Pharmaceutical Sciences, \\ Bayero University, Kano, Nigeria \\ Email: *iaminu.chm@buk.edu.ng
}

How to cite this paper: Aminu, I., Gumel, S.M., Ahmad, W.A. and Idris, A.A. (2020) Adsorption Isotherms and Kinetic Studies of Congo-Red Removal from Waste Water Using Activated Carbon Prepared from Jujube Seed. American Journal of Analytical Chemistry, 11, 47-59.

https://doi.org/10.4236/ajac.2020.111004

Received: November 13, 2019

Accepted: January 18, 2020

Published: January 21, 2020

Copyright $\odot 2020$ by author(s) and Scientific Research Publishing Inc. This work is licensed under the Creative Commons Attribution International License (CC BY 4.0).

http://creativecommons.org/licenses/by/4.0/

\begin{abstract}
In this study, adsorption of Congo red dye onto activated carbon prepared from Jujube (Ziziphus Mauritiania) seeds with phosphoric acid as the activating agent was investigated. Batch adsorption studies were carried out to study the influence of contact time, adsorbent dosage and initial dye concentration on the adsorption. The data was analysed using pseudo-first order and pseudo-second order kinetic models. The pseudo-second order kinetic model was found to describe the adsorption more effectively with a perfect correlation coefficient of unity. The rate constant, $K$ was obtained as $0.182(\mathrm{~g} / \mathrm{mg}$ min) and the calculated $q_{e}(9.81)$ is very close to the experimental value (9.78). A high correlation coefficient obtained when the data was analysed with the intraparticle diffusion rate equation, revealed the presence of intraparticle diffusion in the adsorption process even though it is not the sole controlling step as shown by the value of the intercept $(C \neq 0)$. Isotherm studies showed that there is high correlation in each case when the data was modelled with Langmuir, Freundlich, Temkin and Dubinin-Radushkevic isotherm models but the best fit was obtained with the Freundlich model with $R^{2}=$ 0.9991 , adsorption capacity, $K_{F}=19.73(\mathrm{mg} / \mathrm{g})(\mathrm{mg} / \mathrm{L})^{1 / n}$ and $n=1.563$ indicating the adsorption is favourable and occurs on a heterogeneous surface by multilayer. The study showed that activated carbon from jujube seeds is an effective adsorbent for the removal of Congo red dye from solution.
\end{abstract}

\section{Keywords}

Adsorption, Kinetics, Isotherms, Jujube Seeds, Congo Red

\section{Introduction}

Water pollution caused by the release of colouring materials into the water bo- 
dies is becoming a serious environmental issue. Colored organic effluent is produced in industries such as textiles, rubber, paper, plastic, cosmetics, etc. Some of these coloring materials have been reported to be carcinogenic and mutagenic to aquatic organisms [1]. They are difficult to remove because they are not easily degradable and are highly persistent in the environment [2]. As little as $1 \mathrm{ppm}$ of dyes in water is highly visible, undesirable and toxic which make its removal before discharge into water bodies. Congo red which is an anionic dye widely used in textiles, paper, rubber, and plastic industries. Congo red is extremely toxic, carcinogenic and can cause anaphylactic shock, visual impairment and vomiting in humans [3]. Its removal from wastewater before being discharged into water bodies is therefore imperative from both health and environmental point of view.

Various methods have been used for dye removal such as chemical oxidation, ozonation, biological treatments, irradiation, filtration, reverse osmosis and coagulation. However, the dyes are not totally degraded by these methods because of the stability of the dyes and their xenobiotic nature [4]. An efficient technique for removal of colored material is necessary and adsorption has been effective due to ease of operation, low maintenance costs, high removal efficiency, low energy requirements and safety. Numerous materials adsorbents have been used; however, activated carbon is the most promising candidate owing to its developed porosity, high surface area, large mesopore volume, surface chemistry and its relative high adsorption rates [5]. Various agricultural by-products are potential sources of activated carbon because of their abundance, availability and low cost. Many carbonaceous materials have been used to produce activated carbon such as wood, coal, lignite and coconut shell [6].

In this study, activated carbon was produced from Jujube (Ziziphus mauritiana) seeds, which grows abundantly in northern Nigeria. The seeds are available, inexpensive, however, not extensively investigated for its potential as adsorbent material for dye removal from coloured water. The aim of this work is to produce activated carbon from the jujube seeds via chemical activation with phosphoric acid and study its potential for adsorption of Congo red dye from synthetic wastewater in batch mode. A composite of the activated carbon with zinc oxide was prepared and compared with the as-prepared activated carbon for removal of Congo red. The activated carbons were characterized using FTIR and then used for batch adsorption studies. The influence of operating parameters such as contact time, adsorbent dosage and initial dye concentration were examined to optimize the adsorption process. Kinetics data were fitted to pseudo-first order and pseudo-second order models, and isotherm data fitted to Freundlich, Langmuir, Temkin and Dubinin-Radushkevic isotherm models.

\section{Materials and Methods}

\subsection{Sample Preparation}

The sample (jujube seeds) was bought from Rimi market in Kano state, Nigeria. 
The seeds were washed with distilled water to clean and remove dirt and then dried in an oven at $80^{\circ} \mathrm{C}$. The dried sample was grounded using mortar and pestle.

$50 \mathrm{~g}$ of the grounded sample was weighed into a beaker and digested in $50 \mathrm{ml}$ of phosphoric acid, stirred and left for 24 hours. The sample was then filtered, thoroughly washed with distilled water and then dried at $80^{\circ} \mathrm{C}$ in the oven. The dried sample was put into crucibles and carbonized at $500^{\circ} \mathrm{C}$ for 1 hour. The activated carbon (adsorbent) thus obtained was washed and dried.

\subsection{Preparation of ZnO-Activated Carbon Composite}

To prepare the $\mathrm{ZnO}$-activated carbon composite, $1 \mathrm{~g}$ of $\mathrm{ZnO}$ powder and $1 \mathrm{~g}$ of the activated carbon were added to a beaker containing $100 \mathrm{ml}$ of $1 \%$ acetic acid (99 $\mathrm{ml}$ deionized water and $1 \mathrm{ml}$ acetic acid), the mixture was then transferred to a polyethylene bottle and put into an electric shaker for 20 minutes at $200 \mathrm{rpm}$. After shaking, it was filtered and washed with distilled water, dried in an oven at $50^{\circ} \mathrm{C}$ for 30 minutes.

\subsection{Preparation of Congo Red Dye Stock Solution (Adsorbate)}

A 1000 ppm stock solution of the dye was prepared by dissolving $0.1 \mathrm{~g}$ of Congo red dye in a $100 \mathrm{ml}$ volumetric flask and diluted up to the calibration mark using de-ionized water. 10 ppm, 20 ppm, 30 ppm, 40 ppm and 50 ppm Congo Red dye standard Solutions were prepared by appropriate dilution.

\subsection{Characterization of the Activated Carbon}

FTIR was used to determine the functional groups present on the activated carbon and its composite. Ash content and bulk density were determined using the method of Ahmedna [7] and pH was determined using the method of Al-Gouti et al. [8]. The values were calculated using Equations (2.1) and (2.2).

$$
\begin{aligned}
\text { Ash content }(\%) & =\frac{\text { weight of ash produced }}{\text { initial weight of sample }} \times 100 \\
\text { Bulk density }\left(\mathrm{g} / \mathrm{cm}^{3}\right) & =\frac{\text { weight of dry sample }(\mathrm{g})}{\text { volume of packed dry material }\left(\mathrm{cm}^{3}\right)}
\end{aligned}
$$

\subsection{Batch Adsorption Studies}

Batch studies were conducted by contacting a measured quantity of the adsorbent in $50 \mathrm{ml}$ of the dye solution at constant $\mathrm{pH}$ of 7.2. The samples were put in electric shaker innover 4000 and shaken at $200 \mathrm{rpm}$ at a constant temperature. They were then withdrawn from the shaker at the specified time ambient filtered using Whatman No. 1 filter paper. The filtrates were taken to UV-visible spectrophotometer for determination of absorbance from which the final concentration was determined. The effects of contact time (30 - 150 mins), adsorbent dosage $(0.2-1.0 \mathrm{~g})$ and initial dye concentration $(10-50 \mathrm{ppm})$ on the adsorption were investigated. 
The amount of dye adsorbed per unit mass of adsorbent $(\mathrm{mg} / \mathrm{g})$ was calculated using the Equation (2.3)

$$
q_{e}=\frac{\left(C_{o}-C_{e}\right) V}{m}
$$

where $C_{o}$ is the initial concentration of adsorbate $(\mathrm{mg} / \mathrm{L}), C_{e}$ is the final concentration of adsorbate $(\mathrm{mg} / \mathrm{L}), m$ is the mass of the adsorbent in gram $(\mathrm{g})$ and $V$ is the volume of the adsorbate in liters $(\mathrm{L})$.

The adsorption efficiency can be expressed as percentage adsorption of dye solution as;

$$
\% \operatorname{removal}(R)=\frac{C_{o}-C_{e}}{C_{o}} \times 100
$$

where $C_{o}$ is the initial adsorbate concentration $(\mathrm{mg} / \mathrm{L})$ and $C_{e}$ is the final adsorbate concentration $(\mathrm{mg} / \mathrm{L})$.

\section{Results and Discussion}

\subsection{Characterization of the Adsorbent}

The physical properties of the activated carbon calculated using Equations (2.1) and (2.2) are summarized in Table 1. The values fall within the range reported in most literature. The density of activated carbon suggests a complete carbonization of the plant material. The ash content showed that sufficient amount of the activated carbon was produced. Figure 1 depicts the FT-IR spectrum of both activated carbon and it's composite. Both materials displayed bands at 1145, 1582 , and $1871 \mathrm{~cm}^{-1}$ were respectively attributed to $\mathrm{C}-\mathrm{O}$ stretching, aromatic $\mathrm{C}=\mathrm{C}, \mathrm{C}=\mathrm{O}$ stretching probably from aromatic compound. There is no difference between the two spectra, indicating no chemical interaction between the $\mathrm{ZnO}$ and activated carbon.

\subsection{Effect of Contact Time}

Effect of contact time on adsorption process facilitates the determination of adsorption efficiency and equilibrium time. Figure 2 shows the plot of percent removal against contact time of the adsorption dye onto $\mathrm{AC}$ and the $\mathrm{ZnOAC}$ composite. In both cases, it was observed that percentage removal increases with an increase in contact time. The results indicated that equilibrium time is affected by the modification of the activated carbon; equilibrium was reached around 100 minutes for the $\mathrm{AC}$ and 50 minutes for the $\mathrm{ZnOAC}$. Further increase

Table 1. Physical properties of the activated carbon.

\begin{tabular}{cc}
\hline Property & Value \\
\hline Bulk density $\left(\mathrm{g} / \mathrm{m}^{3}\right)$ & 0.425 \\
Ash content $(\%)$ & 4.25 \\
$\mathrm{pH}$ & 6.30 \\
\hline
\end{tabular}




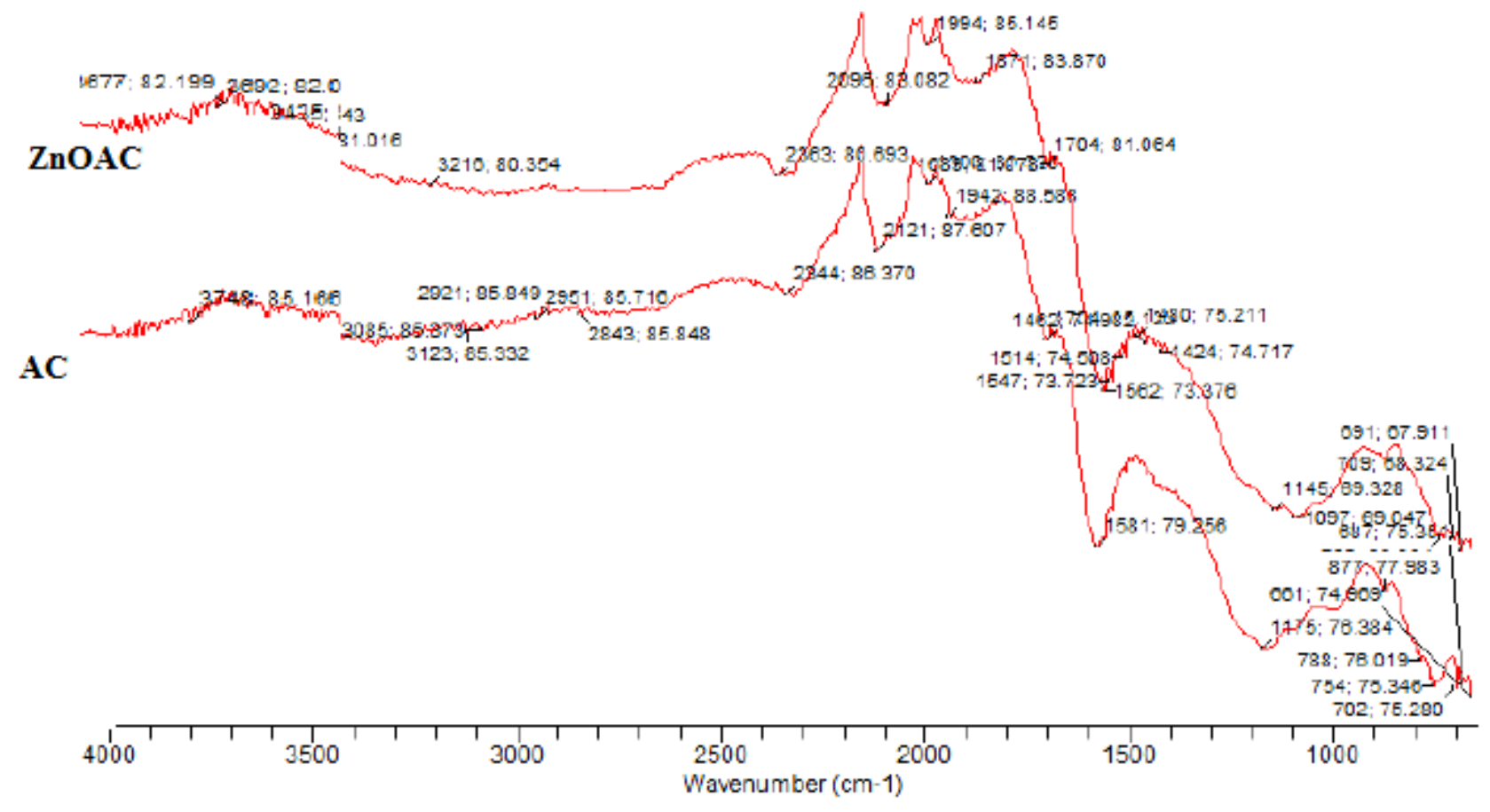

Figure 1. FTIR spectra of prepared activated carbon (AC) and $\mathrm{ZnO}$-Activated carbon composite (ZnOAC).

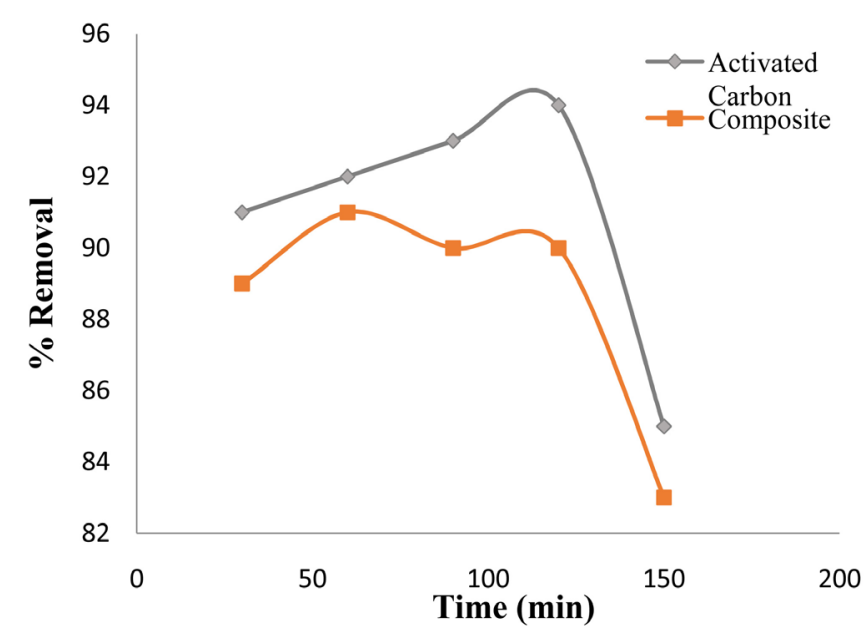

Figure 2. Effect of contact time on percentage removal of Congo red dye onto $\mathrm{AC}$ and $\mathrm{ZnOAC}$ (concentration $10 \mathrm{ppm}$, temperature $30^{\circ} \mathrm{C}, \mathrm{pH} 7.2$ ).

in contact time did not result in any significant adsorption and maximum adsorption was achieved at 120 minutes and 60 minutes for $\mathrm{AC}$ and $\mathrm{ZnOAC}$ respectively. Interestingly, about $90 \%$ removal was achieved in the first 30 minutes of the experiment for both adsorbents. The initial increase in adsorption was due to the presence of free adsorption sites on the surface of the adsorbent which became saturated after some time when the dye molecules have attached themselves onto the adsorbent. The percentage removal for AC was higher than that of $\mathrm{ZnOAC}$, this may be due to the blockage of pores in the activated carbon modified by $\mathrm{ZnO}$ thereby reducing the number of sites in the composite. The 
FT-IR revealed no chemical attraction with surface of the activated carbon. Hence, only AC was used for the remaining experiment and 120 minutes was used as contact time to ensure maximum removal. The initial rapid removal of the dye and the establishment of equilibrium within a short time signifies the efficiency of the adsorbent for wastewater treatment [9].

\subsection{Effect of Adsorbent Dosage}

The effect of adsorbent dosage on the adsorption of Congo red dye was studied between dose range 0.2 - $1.0 \mathrm{~g}$ as shown in Figure 3 It was observed that the adsorption of the dye increased with increasing adsorbent dosage as expected. This is principally due to increased in surface area of the adsorbent, which consequently increases the number of adsorption. The amount of dye adsorbed, however, decreased as the dosage increases as shown in Figure 4 which could be attributed to the overlapping or aggregation of the active sites as the dosage increases which makes the sites inaccessible for the dye [10].

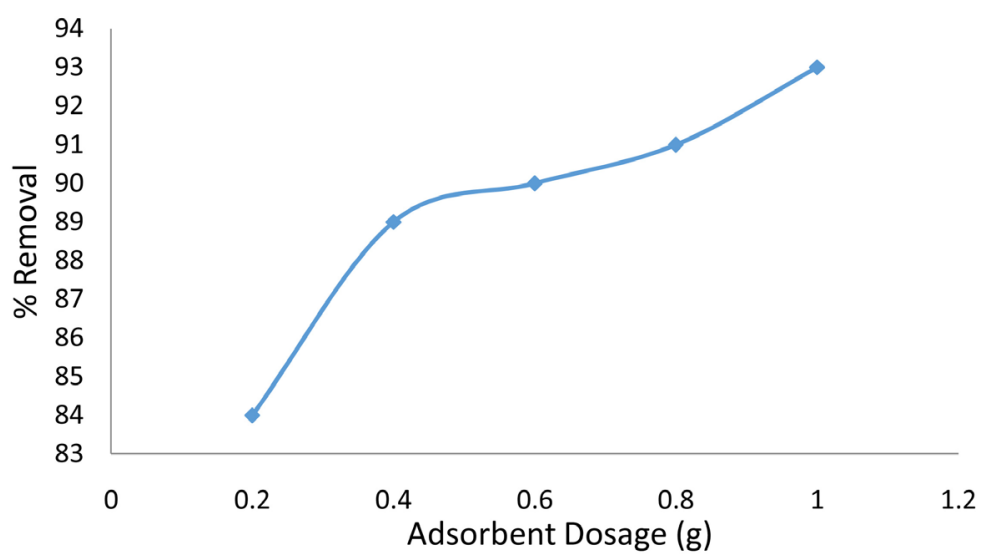

Figure 3. Effect of adsorbent dose on percentage removal of Congo red dye on $\mathrm{AC}$ (Concentration $10 \mathrm{ppm}$, temperature $30^{\circ} \mathrm{C}, \mathrm{pH} 7.2$, contact time 120 mins).

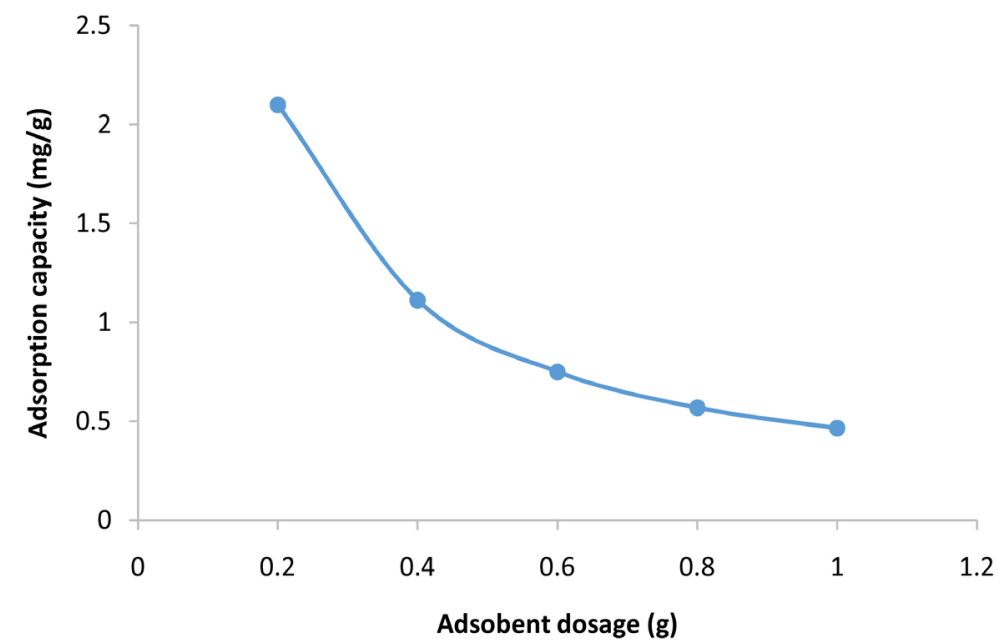

Figure 4. Effect of adsorbent dosage on the dye uptake onto the AC. 


\subsection{Effect of Initial Dye Concentration}

Figure 5 shows the effect of initial dye concentration on the adsorption process. It was observed that adsorption capacity of the dye increases with an increase in initial dye concentration which implies that adsorption process depends on initial dye concentration. A higher concentration of dye provides a higher driving force for dye molecules to approach adsorption sites more rapidly [11]. The rate of diffusion of dye molecules at lower initial dye concentration is slow; hence few dye molecules reach adsorption sites. However, since the same amount of the adsorbent was used, the percentage removal decreases as the initial dye concentration increases as shown in Figure 6.

\subsection{Adsorption Kinetics}

To investigate the kinetics of the adsorption process, the experimental data was analyzed using the pseudo-first order and pseudo-second order models. The adsorption kinetic parameters of the models calculated using Equations (3.1) to (3.3) are shown in Table 2.

The pseudo-first order is expressed as:

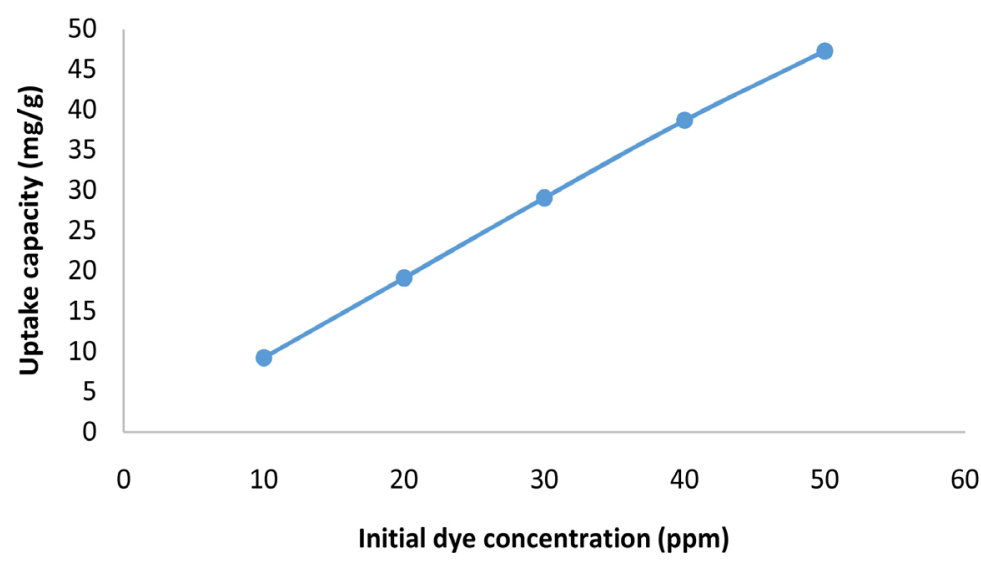

Figure 5. Effect of initial dye concentration on the dye uptake onto the AC (adsorbent dose $1.0 \mathrm{~g}$, temperature $30^{\circ} \mathrm{C}$, contact time 120 mins, $\mathrm{pH}$ 7.2).

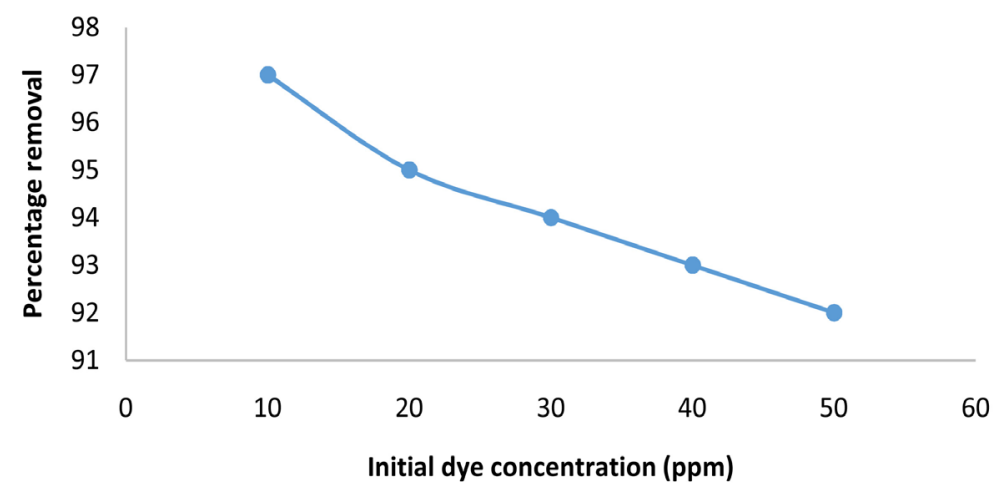

Figure 6. Effect of initial dye concentration on the percentage removal of dye (adsorbent dose $1.0 \mathrm{~g}$, temperature $30^{\circ} \mathrm{C}$, contact time $120 \mathrm{mins}, \mathrm{pH}$ 7.2). 
Table 2. Kinetic parameters.

\begin{tabular}{ccc}
\hline Kinetic Model & Parameter & Value \\
\hline \multirow{2}{*}{ Pseudo-first order } & Exp $q_{e}(\mathrm{mg} / \mathrm{g})$ & 9.78 \\
& $q_{e}(\mathrm{mg} / \mathrm{g})$ & 0.198 \\
& $K_{1}\left(\mathrm{~min}^{-1}\right)$ & 0.018 \\
Pseudo-second order & $R^{2}$ & 0.9776 \\
& $q_{e}(\mathrm{mg} / \mathrm{g})$ & 9.81 \\
& $K_{2}(\mathrm{~g} / \mathrm{mg} \min )$ & 0.182 \\
Intraparticle diffusion rate & $R^{2}$ & 1.00 \\
& $K_{d}\left(\mathrm{mg} / \mathrm{g} \mathrm{min}{ }^{1 / 2}\right)$ & 0.021 \\
& $R^{2}$ & 0.9797 \\
$\log \left(q_{e}-q\right)=\log q_{e}-\left(K_{1} t / 2.303\right)$ &
\end{tabular}

where $q$ is the amount of dye adsorbed $(\mathrm{mg} / \mathrm{g})$ at time $t(\mathrm{~min}), q_{e}$ is the amount of dye adsorbed at equilibrium $(\mathrm{mg} / \mathrm{g})$, and $K_{1}$ is the equilibrium rate constant of pseudo-first order adsorption. $K_{1}$ and $q_{e}$ were obtained from the plot of $\log \left(q_{e}-\right.$ $q)$ against $t$. The $R^{2}$ obtained was high $(0.9776)$ but there is a wide discrepancy between the experimental and the calculated $q_{e}$.

The pseudo-second order model is expressed as:

$$
t / q=1 / K_{2} q_{e}^{2}+t / q_{e}
$$

where $K_{2}$ is the pseudo-second order rate constant. The correlation coefficient $\left(R^{2}=1\right)$ shows a perfect fit of the data to this model and the calculated $q_{e}(9.81)$ is very close to the experimental value (9.78).

Based on the correlation coefficient and the difference between experimental and calculated values of $q_{e}$, the adsorption of Congo red dye unto the activated carbon can best be described by the pseudo-second order model. The model assumes that the rate controlling step is chemisorption promoted by either valency or covalent forces [12].

To identify the step that governs the overall rate of removal, the experimental data was further analysed using the intraparticle diffusion rate equation, expressed as:

$$
q=K_{d} t^{1 / 2}+C
$$

where $K_{d}\left(\mathrm{mg} / \mathrm{g} \mathrm{min}^{1 / 2}\right)$ is the intraparticle diffusion rate constant and $C$ is the intercept. The high value of $R^{2}(0.9797)$ indicates that there was indeed intraparticle diffusion, but it is not the rate controlling step since the intercept $C$ is not equal to zero [13]. Presence of the intercept shows that boundary layer diffusion occurs in the initial stages of the adsorption [14].

\subsection{Adsorption Isotherms}

Adsorption isotherm studies were carried out to understand the interaction between the dye molecules and the activated carbon at equilibrium. This will give 
an indication of the practicability of using the activated carbon for removal of the Congo red dye from wastewater. To establish the most suitable equilibrium curve that can be used for design of adsorption system, the data was analysed using four different isotherm models namely Langmuir, Freundlich, Temkin and Dubinin-Radushkevic. The isotherm parameters of the four models are calculated using Equations (3.4) to (3.9) and presented in Table 3.

Langmuir model assumes that the adsorption occurs on a homogenous surface by monolayer adsorption and there is no interaction between the adsorbed molecules [15]. The linear form of the model is:

$$
\frac{C_{e}}{q_{e}}=\frac{1}{Q_{L} K}+\frac{C_{e}}{Q_{L}}
$$

where $C_{e}$ is the equilibrium concentration $\left(\mathrm{mg} \cdot \mathrm{L}^{-1}\right), q_{e}$ the amount adsorbed at equilibrium ( $\left.\mathrm{mg}^{-1} \mathrm{~g}^{-1}\right), Q_{L}$ is the monolayer adsorption capacity of the adsorbent and $K$ is the Langmuir constant related to adsorption capacity and energy of adsorption. The linear plot of $C_{e} / q_{e}$ versus $C_{e}$ gives a straight line and $Q_{L}$ and $K$ are determined from the slope and intercept of the plot. To determine the favorability of the adsorption using this model, a dimensionless separation factor was calculated, given as

$$
R_{L}=1 /\left[1+K C_{o}\right]
$$

If $0<R_{L}<1$, the adsorption is favorable and if $R_{L}$ is $>1$, it is unfavorable. Results showed that the correlation coefficient was high (0.9523) and $R_{L}$ is 0.21 which shows the adsorption is favorable.

For Freundlich model, the adsorption takes place on a heterogeneous surface by multilayer adsorption. The model is expressed linearly as

$$
\log q_{e}=\log K_{F}+\frac{1}{n} \log C_{e}
$$

Table 3. Equilibrium isotherm parameters.

\begin{tabular}{ccc}
\hline Isotherm Model & Parameter & Value \\
\hline Langmuir & $Q_{L}(\mathrm{mg} / \mathrm{g})$ & 75.76 \\
& $K(\mathrm{~L} / \mathrm{mg})$ & 0.383 \\
Freundlich & $R^{2}$ & 0.9523 \\
& $K_{F}(\mathrm{mg} / \mathrm{g})(\mathrm{mg} / \mathrm{L})^{1 / \mathrm{n}}$ & 19.73 \\
& $N$ & 1.563 \\
Temkin & $R^{2}$ & 0.9991 \\
& $B(\mathrm{mg} / \mathrm{g})$ & 14.483 \\
& $A(\mathrm{~L} / \mathrm{g})$ & 5.052 \\
Dubinin-Radushkevic & $R^{2}$ & 0.9438 \\
& $q_{m}(\mathrm{mg} / \mathrm{g})$ & 37.23 \\
& $B\left(\mathrm{~mol} / \mathrm{kJ}{ }^{2}\right)$ & $1 \times 10^{-7}$ \\
& $R^{2}$ & 0.8714 \\
\hline
\end{tabular}


where $K_{F}(\mathrm{mg} / \mathrm{g})(\mathrm{mg} / \mathrm{L})^{1 / n}$ and $n$ are the Freundlich constants related to adsorption capacity and adsorption intensity, respectively. A plot of $\log q_{e}$ against $\log C_{e}$ gives a straight line with an intercept and slope $K_{F}$ and $1 / n$ respectively. Results showed that there is a good fit of the data to the model $\left(R^{2}=1\right)$ and the value of $n$ (1.563) lies in the range of 1 to 10 which indicates favourable adsorption [16].

The data was further analysed using Temkin isotherm which assumes the adsorption energy decreases linearly with the surface coverage due to adsorbent-adsorbate interactions [17]. It is given as

$$
q_{e}=B \ln A+B \ln C_{e}
$$

where $B=R T / b(\mathrm{mg} / \mathrm{g})$ is the isotherm constant related to heat of adsorption, and $A(\mathrm{~L} / \mathrm{g})$ is the equilibrium binding constant corresponding to the maximum binding energy, $R$ is the gas constant and $T(\mathrm{~K})$ is absolute temperature. $A$ and $B$ were determined from the plot of $q_{e}$ against $\ln C_{e^{e}}$. The values are shown in Table 3.

The Dubinin-Radushkevic isotherm is expressed as:

$$
\ln q_{e}=\ln q_{m}-\beta \varepsilon^{2}
$$

where $q_{m}(\mathrm{mg} / \mathrm{g})$ is the theoretical saturation capacity, $\beta\left(\mathrm{mol}^{2} / \mathrm{J}^{2}\right)$ is a coefficient related to the mean free energy of adsorption, and is the $\varepsilon$ Polanyi expressed as:

$$
\varepsilon=R T \ln \left(1+1 / C_{e}\right)
$$

A plot of $\ln q_{e}$ against $\mathcal{\varepsilon}^{2}$ gives a straight line with $\beta$ and $q_{m}$ obtained from the slope and intercept respectively. The results showed a poor fit for this model.

Among the four isotherm models tested, the data fitted the Freundlich isotherm more closely with $R^{2}=0.9991$. This shows that the adsorption of the Congo red dye unto the activated carbon occurs on a heterogeneous surface by multilayer and the amount of adsorbate adsorbed increases infinitely with an increase in the solute concentration. An approximate indicator of the adsorption capacity is given by $K_{F}=19.73(\mathrm{mg} / \mathrm{g})(\mathrm{mg} / \mathrm{L})^{1 / n}$ and the value of $n(1.563)$ greater than 1 indicates chemisorption reflecting a high affinity between the dye and the adsorbent [18].

\section{Conclusions}

Activated carbon was prepared from Jujube seeds via the chemical method using phosphoric acid as the activating agent. The activated carbon was used as an adsorbent for removal of Congo red from solution. Modifying the activated carbon using $\mathrm{ZnO}$ did not increase the adsorption capacity and the unmodified activated carbon was used for the rest of the experiment. It was concluded that:

- The amount of dye uptake and the percentage removal of the dye by the activated carbon are affected by the contact time, activated carbon dosage and the initial dye concentration.

- The kinetic data is fitted well by the pseudo-second order model which shows that the rate controlling step is chemisorption.

- The mechanism of the adsorption is by boundary layer diffusion in the initial 
stages followed by intraparticle diffusion.

- The Freundlich isotherm model best fits the experimental data which shows that the adsorption is in multilayer and the activated carbon has a heterogeneous surface. Value of $\mathrm{n}$ greater than unity also confirmed the process to be chemisorption.

- This study has shown the potential of activated carbon produced from jujube seeds as a low-cost adsorbent for the removal of colour from Congo red dye solutions. As such, future efforts should be made to determine the adsorption performances activated carbon from jujube seeds in water treatments.

\section{Acknowledgements}

The authors wish to thank Chemistry Department, Bayero University, Kano for providing all the chemicals and equipment for this research.

\section{Conflicts of Interest}

The authors declare no conflicts of interest regarding the publication of this paper.

\section{References}

[1] Lorenc-Grabowska, E. and Gryglewicz, G. (2007) Adsorption Characteristics of Congo Red on Coal Based Mesoporous Activated Carbon. Dyes and Pigments, 74, 34-40. https://doi.org/10.1016/j.dyepig.2006.01.027

[2] Isik, M. and Sponza, D.T. (2005) A Batch Study for Assessing the Inhibition Effects of Direct Yellow 12 in a Mixed Methnogenic Culture. Process Bio-Chemistry, 40, 1053-1062. https://doi.org/10.1016/j.procbio.2004.03.011

[3] Ellenhorn, M. and Barceloux, D. (1988) Medical Toxicology-Diagnosis and Treatment of Human Poisoning. Elsevier Science Publishing Co., New York.

[4] Pearce, C.I., Lloyd, J.R. and Guthrie, J.T. (2003) The Removal of Colour from Textile Wastewater Using Whole Bacterial Cell: A Review. Dyes and Pigments, 58, 179-196. https://doi.org/10.1016/S0143-7208(03)00064-0

[5] Zhang, X., Hao, Y., Wang, X., Chen, Z. and Li, C. (2016) Competitive Adsorption of Cadmium (II) and Mercury (II) Ions from Aqueous Solutions by Activated Carbon from Xanthoceras sorbifolia Bunge Hull. Journal of Chemistry, 2016, Article ID: 4326351. https://doi.org/10.1155/2016/4326351

[6] Hassler, J.W. (1980) Carbon Adsorption Handbook. Ann Arbor Science Publishers, Ann Arbor, MI.

[7] Ahmedna, M., Marshal, W.E. and Rao, M. (2004) Production of Granular Activated Carbon from Select Agricultural by-Products and Evaluation of Their Physical, Chemical and Adsorption Properties. Bioresource Technology, 71, 113-123. https://doi.org/10.1016/S0960-8524(99)00070-X

[8] Al-Gouti, M., Khraisheh, M.A.M., Allen, S. and Ahmad, M.N.M. (2003) The Removal of Dyes from Textile Wastewater: A Study of the Physical Characteristics and Adsorption Mechanisms of Diatomaceous Earth. Journal of Environmental Management, 69, 229-238. https://doi.org/10.1016/j.jenvman.2003.09.005

[9] Iqbal, M. and Ashiq, M. (2010) Thermodynamics and Kinetics of Adsorption of Dyes from Aqueous Media onto Alumina. Journal of the Chemical Society of Pakistan, 
$32,419-428$.

[10] Akar, S. and Ozcan, A. (2009) Biosorption of a Reactive Textile Dye from Aqueous Solutions Utilizing an Agro-Waste. Desalination, 249, 757-761. https://doi.org/10.1016/j.desal.2008.09.012

[11] Das, B. and Mondal, N. (2011) Calcareous Soil as a New Adsorbent to Remove Lead from Aqueous Solution: Equilibrium, Kinetic and Thermodynamic Study. Environmental Research and Technology, 1, 515-530.

[12] Ho, Y. and McKay, G. (2000) The Mechanics of Sorption of Divalent Metal Ions unto Sphagnum Moss Peat. Water Research, 34, 735-742.

https://doi.org/10.1016/S0043-1354(99)00232-8

[13] Akpomie, K. and Dawodu, F. (2014) Efficient Abstraction of Nickel (II) and Manganese (II) Ions from Solution onto an Alkaline-Modified Montmorillonite. Journal of Taibah University for Science, 8, 343-355. https://doi.org/10.1016/j.jtusci.2014.05.001

[14] Acharya, J., Sahu, J., Sahoo, B., Mohanty, C. and Meikap, B. (2009) Removal of Chromium(VI) from Wastewater by Activated Carbon Developed from Tamarind Wood Activated with Zinc Chloride. Chemical Engineering Journal, 150, 25-39. https://doi.org/10.1016/j.cej.2008.11.035

[15] Babel, S. and Kurniawan, T.A. (2004) Cr(VI) Removal from Synthetic Wastewater Using Coconut Shell Charcoal and Commercial Activated Carbon Modified with Oxidizing Agent and/or Chitosan. Chemosphere, 54, 951-967.

https://doi.org/10.1016/j.chemosphere.2003.10.001

[16] Slejko, F. (1985) Adsorption Technology: A Step by Step Approach Process. Marcel Dekker, New York.

[17] Adekola, F., Hodonou, D. and Adegoke, H. (2014) Thermodynamic and Kinetic Studies of Biosorption of Iron and Manganese from Aqueous Medium Using Rice Husk Ash. Applied Water Science, 6, 319-330. https://doi.org/10.1007/s13201-014-0227-1

[18] Jiang, J., Cooper, C. and Ouki, S. (2002) Comparison of Modified Montmorillonite Adsorbents-Part 1: Preparation, Characterization and Phenol Adsorptio. Chemosphere, 47, 711-716. https://doi.org/10.1016/S0045-6535(02)00011-5 


\section{Appendix}

Jujube seed

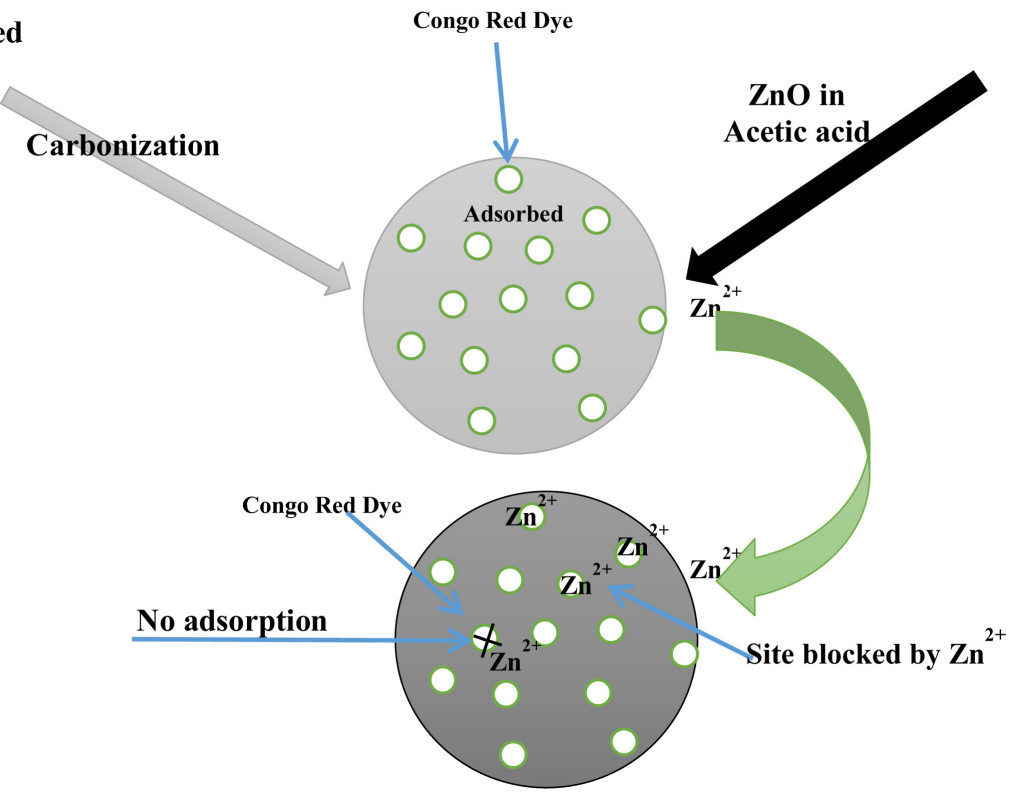

